\title{
The normal choroidal thickness in southern Thailand
}

\author{
This article was published in the following Dove Press journal: \\ Clinical Ophthalmology \\ II November 2014 \\ Number of times this article has been viewed
}

\author{
Pichai Jirarattanasopa' \\ Nisa Panon ${ }^{2}$ \\ Siriphun Hiranyachattada ${ }^{2}$ \\ Patama Bhurayanontachai' \\ 'Department of Ophthalmology, \\ Faculty of Medicine, ${ }^{2}$ Department \\ of Physiology, Faculty of Science, \\ Prince of Songkla University, Hat Yai, \\ Thailand
}

Objective: To investigate the association between subfoveal choroidal thickness in healthy southern Thailand volunteers and age, axial length, and refractive error.

Subjects and methods: This was a prospective cross-sectional case series. A total of 210 eyes of 105 healthy volunteers ( 86 women, age 23-83 years) in southern Thailand were examined with enhanced depth-imaging optical coherence tomography. Subjects with systemic diseases that may affect the choroidal vascular blood vessels, such as diabetes, impaired renal function, and hypertension, were excluded. Refractive error and axial length were measured by autorefractometry and an IOLMaster, respectively. Subfoveal choroidal thickness was measured from the outer border of the retinal pigment epithelium to the inner scleral border in the subfoveal area.

Results: The mean subfoveal choroidal thickness was $279.4 \pm 75.49 \mu \mathrm{m}$, and the mean age was $46.4 \pm 16.45$ years. Subfoveal choroidal thickness was negatively correlated with age $\left(r^{2}=0.33\right.$, $P<0.0001)$ and axial length $\left(r^{2}=0.02, P<0.02\right)$. Multivariable regression analysis showed subfoveal choroidal thickness was positively and negatively correlated with a spherical equivalent refractive error and axial length, respectively, when adjusted for age.

Conclusion: Age is the most important factor in choroidal thickness rather than axial length and refractive error. Subfoval choroidal thickness was decreased $2.67 \mu \mathrm{m}$ every year and $14.59 \mu \mathrm{m}$ with $1 \mathrm{~mm}$ increase in axial length.

Keywords: choroidal thickness, enhanced depth-imaging optical coherence tomography, swept-source optical coherence tomography

\section{Introduction}

The choroid is located at the part that lies between the scleral and the retinal layer of the eye. It is an important tissue due to its highly vascular structure, ${ }^{1}$ and mainly supplies oxygen and nutrients to the outer retina, including the photoreceptor layer and retinal pigment epithelium. ${ }^{2}$ The changing of the choroid has been proposed to play a significant role in the pathogenesis of many chorioretinal diseases, such as age-related macular degeneration, ${ }^{3}$ polypoidal choroidal vasculopathy, ${ }^{4}$ central serous chorioretinopathy, ${ }^{5}$ high myopia-related chorioretinal atrophy, ${ }^{6}$ and Vogt-KoyanagiHarada disease. ${ }^{7}$

Spectral domain optical coherence tomography (OCT) has the ability to image the retina and display even small retinal details of the photoreceptor layer and choroid. When Spaide et $\mathrm{al}^{8}$ introduced enhanced depth imaging (EDI)-OCT based on spectral domain OCT technology, using this technique combined with an image-averaging and eye-tracking system, the sensitivity of the choroidal imaging was enhanced and the images were clearer. Recently, imaging technology using EDI techniques (based on commercial spectral domain OCT at $840 \mathrm{~nm}$ ) or high-penetrating swept-source OCT using $1 \mu \mathrm{m}$ probe-wavelength has been used to assess the choroidal cross-sectional structure and its thickness. ${ }^{8-10}$
Correspondence: Pichai Jirarattanasopa Department of Ophthalmology, Faculty of Medicine, Prince of Songkla University, I5 Karnjanavanit Road, Hat Yai, Songkhla 90110 , Thailand

Fax +66 874429619

Email jirarapichai@gmail.com 
Several studies have reported that choroidal thickness is associated with age, refractive error (RE), and axial length. ${ }^{9-22}$ However, in the Thai population, it has not been reported. In this study, the subfoveal choroidal thickness of 105 healthy southern Thai volunteers was measured in order to determine the normal profile and its correlations with age, axial length, and RE.

\section{Subjects and methods}

This study was conducted in accordance with the tenets of the Declaration of Helsinki, and was approved by the institutional review boards and the medical ethics committee at Prince of Songkla University. Informed consent was obtained from all participants after explaining the possible consequences of the study.

\section{Subjects}

Both eyes of 105 healthy southern Thai volunteers (86 women, 19 men, age 23-83 years) with no visual complaints, between June 2013 and March 2014, were recruited for this study. Exclusion criteria included high myopia or hyperopia greater than -6 or $+6 \mathrm{D}$ of spherical equivalent RE, previous ocular disease, history of ophthalmic surgery, and poor image quality due to unstable fixation or severe cataracts. Subjects with systemic diseases that may affect the choroidal vascular blood vessels, such as diabetes, impaired renal function, and hypertension, were excluded.

\section{Methods}

All subjects underwent ophthalmologic examination, including best-corrected visual acuity, intraocular pressure measurement, axial length, spherical equivalent of RE, color fundus photography, and OCT with a Cirrus HD-OCT (Carl Zeiss Meditec, Dublin, CA, USA) with and without EDI mode were recorded. The EDI-OCT was performed between 1 and $3 \mathrm{pm}$ to prevent circadian variations. Subfoveal choroidal thickness was measured from the vertical distance between the outer border of the hyperreflective line corresponding to the retinal pigment epithelium and the inner surface of the hyperreflective line corresponding to the chorioscleral interface at the fovea region. To maximize the signal-to-noise ratio, new software generated a highdefinition one-line raster scan by capturing $20 \mathrm{~B}$-scans at a single location and applying unique Selective Pixel Profiling ${ }^{\mathrm{TM}}$ software to the scans to obtain a higher-quality image. With segmentation methods, subfoveal choroidal thickness was measured retrospectively using the planimetric-scale software in the device (Figure 1). Both hyperreflective lines

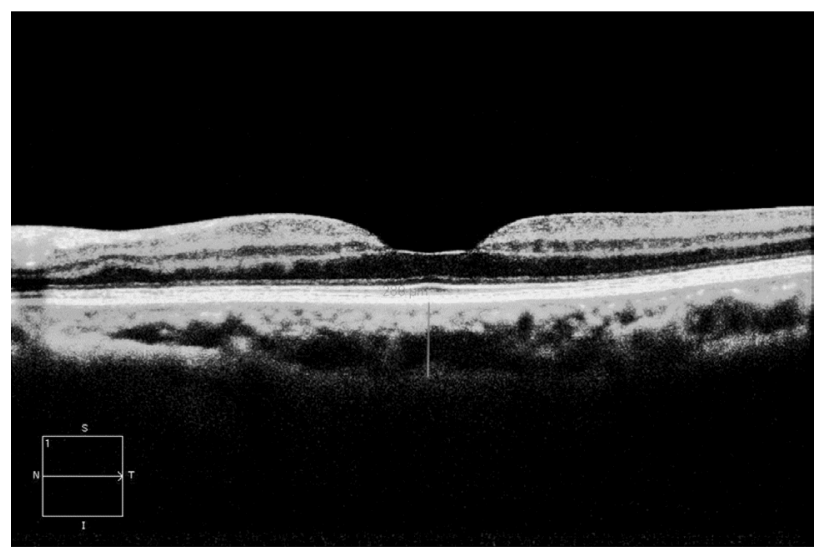

Figure I From cirrus high-definition Optical Coherence Tomography, high-definition one-line raster-scan protocol with capturing 20 B-scans at a single location and applying unique Selective Pixel Profiling ${ }^{\mathrm{TM}}$ software on enhanced depth imaging mode to obtained high quality image.

were determined, and subfoveal choroidal thickness was measured by a trained ophthalmologist (PJ).

RE was measured with an autorefractometer (PRK-5000; Potec, Daejeon, South Korea), and the spherical equivalent RE was calculated. Axial length was measured by partial-coherence interferometry (IOLMaster ${ }^{\circledR}$ 500; Carl Zeiss Meditec). All IOLMaster 500, autorefractometry, and EDI-OCT examinations were performed by a physician in training (NP).

\section{Statistical analysis}

All data are expressed as means \pm standard deviation (SD). Sex and side were compared with subfoveal choroidal thickness using multiway analysis of variance. Regression analysis was used to analysis age, spherical equivalent RE, axial length, intraocular pressure, and central foveal thickness with subfoveal choroidal thickness. Multivariableregression analysis was used to analyze the independent variables of age, spherical RE, and axial length with respect to the dependent variable of subfoveal choroidal thickness. Values of $P<0.05$ were considered to indicate statistical significance.

\section{Results}

Data from 210 eyes of 105 healthy volunteers (86 women, 19 men) in southern Thailand with normal foveal contour, no retinal pathology, and no abnormality of the choroid were analyzed. The overall mean $( \pm \mathrm{SD})$ age was $46.4 \pm 16.45$ years (range $23-83$ years), with $40.0 \pm 16.66$ years in males and $47.81 \pm 16.15$ years in females $(P=0.072)$. The mean $( \pm \mathrm{SD})$ intraocular pressure, spherical equivalent RE, axial length, central foveal thickness of the retina, and subfoveal choroidal thickness were $12.38 \pm 2.47 \mathrm{mmHg}$ (range $6.0-19.0 \mathrm{mmHg}$ ), 
Table I Demographic data

\begin{tabular}{llll}
\hline & Mean \pm SD & Minimum & Maximum \\
\hline Age & $46.37 \pm 16.45$ & 23 & 83 \\
IOP & $12.38 \pm 2.47$ & 6.0 & 19.0 \\
Axial length & $23.31 \pm 0.84$ & 21.63 & 26.10 \\
Spherical equivalent of RE & $-0.54 \pm 1.13$ & -3.93 & 2.31 \\
Central foveal thickness & $238.8 \pm 24.16$ & 122.0 & 343.0 \\
Subfoveal choroidal thickness & $279.4 \pm 75.49$ & 76 & 490 \\
\hline
\end{tabular}

Abbreviations: IOP, intraocular pressure; RE, refractive error.

$-0.54 \pm 1.13 \mathrm{D}$ (range -3.93 to $2.31 \mathrm{D}$ ), $23.31 \pm 0.84 \mathrm{~mm}$ (range $21.63-26.10 \mathrm{~mm}$ ), $238.8 \pm 24.16 \mu \mathrm{m}$ (range $122-343 \mu \mathrm{m}$ ), and 279.4 $\pm 75.49 \mu \mathrm{m}$ (range 76-490 $\mu \mathrm{m}$ ), respectively (Table 1). There was no statistically significant difference in subfoveal choroidal thickness with regard to sex $(P=0.327)$, laterality ( $P=0.338)$, intraocular pressure $(P=0.118)$, spherical equivalent $\operatorname{RE}(P=0.571)$, or central foveal thickness $(P=0.805)$ (Table 2).

Subfoveal choroidal thickness showed a negative correlation with age $(P<0.0001)$ with a regression coefficient of $r^{2}=0.33$. With the regression formula, subfoveal choroidal thickness decreased approximately $2.67 \mu \mathrm{m}$ for every year's increase in age (Figure 2).

Subfoveal choroidal thickness showed a negative correlation with axial length $(P=0.020)$; however, the regression coefficient was low $\left(r^{2}=0.021\right)$. With the regression formula, subfoveal choroidal thickness decreased approximately $14.59 \mu \mathrm{m}$ for every $1 \mathrm{~mm}$ increase in axial length (Figure 3).

With multiple regression analysis, subfoveal choroidal thickness showed statistical significance with spherical equivalent RE when adjusted for age $\left(r^{2}=0.35, P=0.007\right)$ and axial length when adjusted for age $\left(r^{2}=0.34, P=0.034\right)$.

\section{Discussion}

Several researchers have reported on mean subfoveal choroidal thickness in normal eyes. ${ }^{10-20}$ Our study of a healthy

Table 2 Univariable linear regression-model analysis of subfoveal choroidal thickness with age, IOP, spherical equivalent RE, and axial length

\begin{tabular}{lll}
\hline Factors & \multicolumn{2}{l}{$\begin{array}{l}\text { Mean subfoveal choroidal } \\
\text { thickness }\end{array}$} \\
\cline { 2 - 3 } & $\boldsymbol{r}^{\mathbf{2}}$ & $\boldsymbol{P}$ \\
\hline Age & 0.33 & $<0.000$ *** $^{*}$ \\
IOP & 0.007 & 0.118 \\
Spherical equivalent RE & 0.003 & 0.571 \\
Axial length & 0.021 & $0.020^{* *}$ \\
\hline
\end{tabular}

Note: **Significant.

Abbreviations: IOP, intraocular pressure; RE, refractive error.

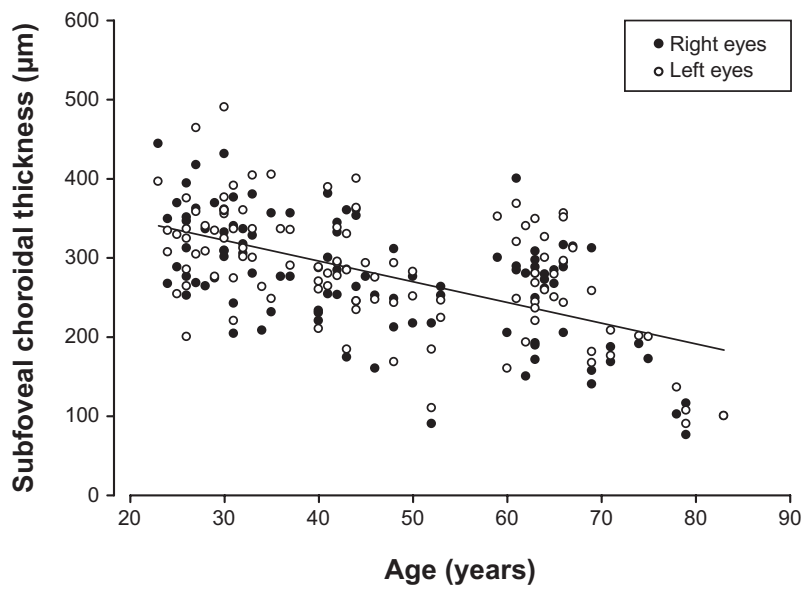

Figure 2 Scatter plot of age and subfoveal choroidal thickness of all volunteers shows a significant negative correlation $\left(y=402.4-2.67 x, r^{2}=0.33 ; P<0.0001\right)$.

southern Thai population showed a mean $( \pm \mathrm{SD})$ subfoveal choroidal thickness of $279.4 \pm 75.49 \mu \mathrm{m}$ with a mean age of 46.37 years, which was less than a Korean population ${ }^{11}$ $(307.3 \pm 95.2 \mu \mathrm{m})$ with a mean age of 40.18 years and an adult Spanish population ${ }^{21}(305.6 \pm 102.6 \mu \mathrm{m})$ with a mean age of 53 years. However, it was greater than Chinese popula$\operatorname{tion}^{14}(261.9 \pm 88.4 \mu \mathrm{m})$ with a mean age of 49.73 years and a Japanese population ${ }^{15}(265.5 \pm 82.4 \mu \mathrm{m})$ with a mean age of 45.7 years. The differences in mean subfoveal choroidal thickness may result from differences in the mean age of each study. Other possible reasons could be differences in the axial length, RE, ethnicity, and different OCT instruments ${ }^{22,23}$ and measuring software. ${ }^{16}$

Li et $\mathrm{al}^{18}$ investigated subfoveal choroidal thickness in young Danish adults. They found that the subfoveal choroid was thicker in males than in females. Similarly, in the study of Wei et al ${ }^{13}$ who investigated subfoveal choroidal thickness

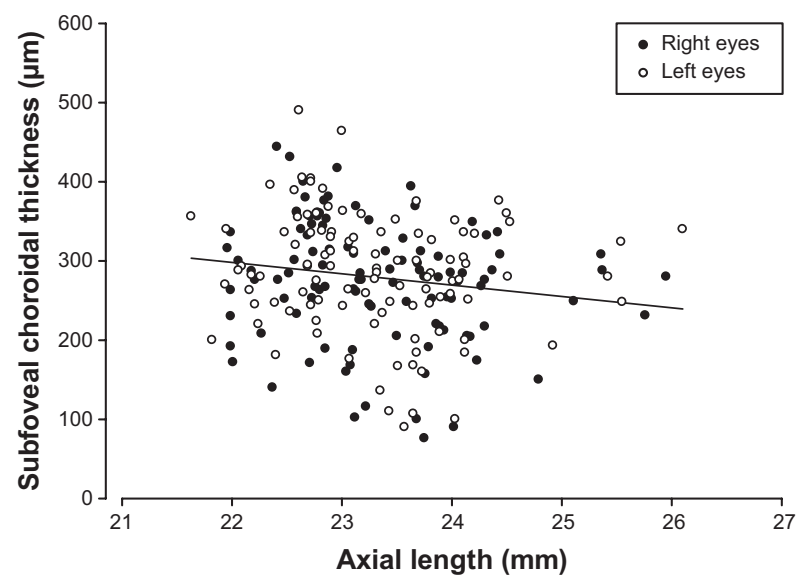

Figure 3 Scatter plot of axial length and subfoveal choroidal thickness of all volunteers shows a significant negative correlation $\left(y=6 \mid 8.5-14.59 x, r^{2}=0.021 ; P=0.020\right)$. 
in older Chinese, found the subfoveal choroid to be thicker in males than females. They postulated that the sex hormone may affect the choroidal blood flow and explained why the age-related macular degeneration is more frequently found in females than in males. The study of Fujiwara et $\mathrm{al}^{15}$ in Japan (and our study) showed the subfoveal choroid to be slightly thicker in males; however, it did not show a statistical significance. The higher mean age and the larger numbers of females that were included in our study may have influenced this discrepancy. Future studies are needed to explore this association.

In the present study, subfoveal choroidal thickness was strongly negatively correlated with age $\left(r^{2}=0.33, P<0.0001\right)$, similar to several studies that reported an age-related decline in choroidal thickness. . $^{8,10,12,13,15-17,20}$ Based on the regressive formula (Figure 2), subfoveal choroidal thickness decreased approximately $2.67 \mu \mathrm{m}$ every year. This correlation was supported by a histologic study that showed a decrease in choriocapillaris density, choriocapillaris diameter, and choroidal thickness in advanced ages. ${ }^{24}$ In addition, this correlation also confirmed the age-related choroidal atrophy that was proposed by Spaide. ${ }^{25}$

Previous studies reported a negative correlation between choroidal thickness and axial length. ${ }^{10,11,13,15-18}$ This is also reported in our study. Based on the regressive formula (Figure 3), subfoveal choroidal thickness decreased approximately $14.59 \mu \mathrm{m}$ for every $1 \mathrm{~mm}$ of axial length. Our study suggests that age may be the most important factor of subfoveal choroidal thinning, rather than axial length, due to a higher level of significance and higher correlation coefficient. This study did not show a correlation between subfoveal choroidal thicknesses and spherical equivalent RE. When adjusted for age, both spherical equivalent and axial length showed a statistically significant correlation (choroidal thickness $=419.01-2.91 \times$ age $+10.70 \times$ standard error $[D]$ and Choroidal thickness $=653.62-2.26 \times$ age $-10.86 \times$ axial length [mm]). These results support previous studies of choroidal thickness in high myopia, ${ }^{26,27}$ which showed an association with a higher degree of myopia or longer axial length and thinner choroid. Additionally, there was a decrease of choroidal blood flow in high myopia. A previous study of choroidal thickness in uveal effusion syndrome ${ }^{28,29}$ showed significant choroidal thickening and a prevalent increase in hyperopic eyes or smaller axial length.

There has been no comparable normative data available in the Thai population. This study identified normal subfoveal choroidal thickness profiles and its association. In addition, it can be used for monitoring and further studies of choroidal thickness changes in various chorioretinal diseases in the Thai population.

There were some limitations in this study. Although EDI-OCT increases choroid-image sensitivity, in some cases a thick pigmented retinal pigment epithelium and light scattering will occur. Therefore, the visualization of the chorioscleral interface in the foveal region is not clearly visible in a few subjects. Another limitation was the distribution of population in this study, which did not reflect the normal population because of the relatively small sample size and large percentage of women.

In conclusion, the mean subfoveal choroidal thickness was $279.4 \pm 75.49 \mu \mathrm{m}$, with a mean age and axial length of 46.37 years and $23.31 \mathrm{~mm}$, respectively, in a healthy southern Thai population. Subfoveal choroidal thickness was $2.67 \mu \mathrm{m}$, with a $14.59 \mu \mathrm{m}$ decrease for every year and a $1 \mathrm{~mm}$ increase in axial length. Age is the most important factor in choroidal thickness rather than axial length and RE.

\section{Acknowledgment}

This research was supported by a Grant-in-Aid for Scientific Research (56-10-50-21-2) from Prince of Songkla University, Songkhla, Thailand.

\section{Disclosure}

The authors report no conflicts of interest in this work.

\section{References}

1. Nickla DL, Wallman J. The multifunctional choroid. Prog Retin Eye Res. 2010;29:144-168.

2. Linsenmeier RA, Padnick-Silver L. Metabolic dependence of photoreceptors on the choroid in the normal and detached retina. Ophthalmol Vis Sci. 2000;41:3117-3123.

3. Koizumi H, Yamagishi T, Yamazaki T, Kawasaki R, Kinoshita S. Subfoveal choroidal thickness in typical age-related macular degeneration and polypoidal choroidal vasculopathy. Graefes Arch Clin Exp Ophthalmol. 2011;249:1123-1128.

4. Okubo A, Sameshima M, Uemura A, Kanda S, Ohba N. Clinicopathological correlation of polypoidal choroidal vasculopathy revealed by ultrastructural study. Br J Ophthalmol. 2002;86:1093-1098.

5. Guyer DR, Yannuzzi LA, Slakter JS, Sorenson JA, Ho A, Orlock D. Digital indocyanine green videoangiography of central serous chorioretinopathy. Arch Ophthalmol. 1994;112:1057-1062.

6. Duke-Elder S, Abrams D. Pathological myopia. In: Duke-Elder S, editor. System of Ophthalmology: Ophthalmic Optics and Refraction. London: Mosby; 1970:300-362.

7. Marulo I, Lida T, Sugano Y, et al. Subfoveal choroidal thickness after treatment of Vogt-Koyanaki-Harada disease. Retina. 2011;31: 510-517.

8. Spaide RF, Komizumi H, Pozzoni MC. Enhanced depth imaging spectral-domain optical coherence tomography. Am J Ophthalmol. 2008; 46:496-500.

9. Margolis R, Spaide RF. A pilot study of enhanced depth imaging optical coherence tomography of choroid in the normal eyes. Am J Ophthalmol. $2009 ; 147: 811-815$ 
10. Hirata M, Tsujikawa A, Matsumoto A, et al. Macular choroidal thickness and volume in normal subjects measured by swept-source optical coherence tomography. Invest Ophthalmol Vis Sci. 2011;52: 4971-4978.

11. Kim M, Kim SS, Koh HJ, Lee SC. Choroidal thickness, age and refractive error in healthy Korean subjects. Optom Vis Sci. 2014;91:491-496.

12. Shin JW, Shin YU, Cho HY, Lee BR. Measurement of choroidal thickness in normal eyes using 3D OCT-1000 spectral domain optical coherence tomography. Korean J Ophthalmol. 2012;26:255-259.

13. Wei WB, Xu L, Jonas JB, et al. Subfoveal choroidal thickness: the Beijing Eye Study. Ophthalmology. 2013;120(1):175-180.

14. Ding X, Li J, Zeng J, et al. Choroidal thickness in healthy Chinese subjects. Invest Ophthalmol Vis Sci. 2011;52:9555-9560.

15. Fujiwara A, Shiragami C, Shirakata Y, Manabe S, Izumibata S, Shiraga F. Enhanced depth imaging spectral-domain optical coherence tomography of subfoveal choroidal thickness in normal Japanese eyes. Jpn J Ophthalmol. 2012;56:230-235.

16. Agawa T, Miura M, Ikuno Y, et al. Choroidal thickness measurement in healthy Japanese subjects by three-dimensional high-penetration optical coherence tomography. Graefes Arch Clin Exp Ophthalmol. 2011;249:1485-1492.

17. Ikuno Y, Kawaguchi K, Nouchi T, Yasuno Y. Choroidal thickness in healthy Japanese subjects. Invest Ophthalmol Vis Sci. 2010;51: 2173-2176.

18. Li XQ, Larsen M, Munch IC. Subfoveal choroidal thickness in relation to sex and axial length in 93 Danish university students. Invest Ophthalmol Vis Sci. 2011;52:8438-8441.

19. Kin SW, Oh J, Kwon SS, Yoo J, Huh K. Comparison of choroidal thickness among patients with healthy eyes, early age-related maculopathy, neovascular age-related macular degeneration, central serous chorioretinopathy, and polypoidal choroidal vasculopathy. Retina. 2011;31:1904-1911.
20. Manjunath V, Taha M, Fujimoto JG, Duker JS. Choroidal thickness in normal eyes measured using Cirrus HD optical coherence tomography. Am J Ophthalmol. 2010;150:325-329.

21. Ruiz-Moreno JM, Flores-Moreno I, Lugo F, Ruiz-Medrano J, Montero JA, Akiba M. Macular choroidal thickness in normal pediatric population measured by swept-source optical coherence tomography. Invest Ophthalmol Vis Sci. 2013;54:353-359.

22. Copete S, Flores-Moreno I, Montero JA, Duker JS, Ruiz-Moreno JM. Direct comparison of spectral-domain and swept-source OCT in the measurement of choroidal thickness in normal eyes. Br J Ophthalmol. 2014;98:334-338

23. Matsuo Y, Sakamoto T, Yamashita T, Tomita M, Shirasawa M, Terasaki H Comparisons of choroidal thickness of normal eyes obtained by two different spectral-domain OCT instruments and one swept-source OCT instrument. Invest Ophthalmol Vis Sci. 2013;54:7630-7636.

24. Ramrattan RS, van der Schaft TL, Mooy CM, de Bruijn WC, Mulder PG, de Jong PT. Morphometric analysis of Bruch's membrane, the choriocapillaris, and the choroid in aging. Invest Ophthalmol Vis Sci. 1994; 35:2857-2864.

25. Spaide RF. Age-related choroidal atrophy. Am J Ophthalmol. 2009;147: 801-810.

26. Ikuno Y, Tano Y. Retinal and choroidal biometry in highly myopic eyes using spectral-domain optical coherence tomography. Invest Ophthalmol Vis Sci. 2009;50:3876-3880.

27. Nishida Y, Fujiwara T, Imamura Y, Lima LH, Kurosaka D, Spaide RF. Choroidal thickness and visual acuity in highly myopic eyes. Retina. 2012;32:1229-1236

28. Elagouz M, Stanescu-Segall D, Jackson TL. Uveal effusion syndrome. Surv Ophthalmol. 2010;55:134-145.

29. Harada T, Machida S, Fujiwara T, Nishida Y, Kurosaka D. Choroidal findings in idiopathic uveal effusion syndrome. Clin Ophthalmol.2011; 5:1599-1601.
Clinical Ophthalmology

\section{Publish your work in this journal}

Clinical Ophthalmology is an international, peer-reviewed journa covering all subspecialties within ophthalmology. Key topics include: Optometry; Visual science; Pharmacology and drug therapy in eye diseases; Basic Sciences; Primary and Secondary eye care; Patient Safety and Quality of Care Improvements. This journal is indexed on

\section{Dovepress}

PubMed Central and CAS, and is the official journal of The Society of Clinical Ophthalmology (SCO). The manuscript management system is completely online and includes a very quick and fair peer-review system, which is all easy to use. Visit http://www.dovepress.com/ testimonials.php to read real quotes from published authors. 